\title{
STRATEGI KEMITRAAN DI PT. DIF NUSANTRA DAN BALI FRESH FEMALE FARMERS GROUP (BFFFG) DI DESA KEDISAN, KECAMATAN KINTAMANI, KABUPATEN BANGLI, BALI.
}

\section{PARTNERSHIP STRATEGY IN PT. DIF NUSANTARA AND BALI FRESH FEMALE FARMERS GROUP (BFFFG) IN KEDISAN VILLAGE, KINTAMANI DISTRICT, BANGLI REGENCY, BALI.}

\author{
L. Anggraini ${ }^{1}$, A. Yusdiarti ${ }^{1 \mathrm{a}}$ dan W. Nahraeni ${ }^{1}$ \\ ${ }^{1}$ Jurusan Agribisnis, Fakultas Pertanian Universitas Djuanda Bogor \\ Jalan Tol Ciawi No. 1 Kotak Pos 35 Bogor 16720 \\ a'Korespondensi: Arti Yusdiarti. Telp: 089630194646; E-mail: artiyusdiarti@gmail.com
}

\begin{abstract}
This study was aimed to identify internal and external factors in BFFFG, develope alternative strategies to conduct SWOT analysis. The study was done in Kedisan Village, Kintamani District, Bangli Regency, Bali. Data were collected for 4 months from 12 June to 2 October 2006 through direct interview by using open questionnaires and discussion. IFE, EFE, and SWOT analysis. Based on the results of SWOT analysis, strategies were developed. These included introducing "Bali Fresh" products to areas outside Bali island, maintaining the company's marketing strategies, and utilizing abandoned vegetables to open new opportunity for the company. Several recommendations given were : the establishment of kindergarten for children of partner farmers, adding more young labors, transparency on harvested product price. For PT DIF Nusantara, it was recommended that new consumers be sought in order to reduce wasted vegetables.
\end{abstract}

Keywords: Strategy, Working time allocation, SWOT

\begin{abstract}
ABSTRAK
Penelitian ini bertujuan untuk mengidentifikasi faktor-faktor internal dan eksternal dalam kerjasama kemitraan BFFFP antara PT DIF dan BFFFG, menyusun alternatif strategi dengan melakukan analisis SWOT. Penelitian ini dilakukan di desa Kedisan, Kecamatan Kintamani, Kabupaten Bangli, Bali. Pengumpulan data dilakukan selama 4 bulan mulai 12 Juni sampai 2 Oktober 2006 dengan cara wawancara langsung. Analisis data menggunakan Matriks IFE, IFE, dan SWOT. Strategi dengan analisis SWOT yaitu dapat memperkenalkan produk "Bali Fresh" keluar pulau Bali, menjaga strategi pemasaran perusahaan dan memanfaatkan sayuran yang hampir tidak terpakai untuk membuka peluang baru bagi perusahaan. Rekomendasi dari penelitian ini : didirikannya sarana taman kanak-kanak bagi anak petani mitra, menambah jumlah tenaga kerja muda, lebih transparan tentang harga hasil panen dan agar PT. DIF Nusantara mencari konsumen yang dapat mengurangi jumlah sayuran yang terbuang.
\end{abstract}

Kata Kunci : Strategi, Curahan Kerja, dan SWOT 


\section{PENDAHULUAN}

Hortikultura merupakan salah satu subsektor pertanian yang memiliki peranan sangat besar dalam perekonomian nasional. Salah satu indikator ekonomi makro yang cukup penting untuk mengetahui peranan dan kontribusi yang diberikan oleh subsektor hortikultura terhadap pendapatan nasional adalah dengan melihat nilai Produk Domestik Bruto (PDB). Sejauh ini kontribusi hortikultura pada pembentukan PDB memperlihatkan kecenderungan yang meningkat dan kontribusi PDB terbesar masih dari buah-buahan dan sayuran. Permintaan sayuran semakin tinggi, ini disebabkan oleh adanya permintaan dari jumlah penduduk Indonesia maupun turis mancanegara. Di Bali jumlah turis terus meningkat, sehingga menyebabkan permintaan semakin meningkat.

PT. DIF Nusantara sebagai perusahaan yang memasarkan produk sayuran yang segar memerlukan jumlah produksi secara kontinue, dan dari kebunnya sendiri belum bisa memenuhi permintaan konsumen dan sistem jadwal tanam yang belum sesuai pula, sehingga PT. DIF Nusantara melakukan kemitraan dengan dengan kelompok petani wanita yang bergerak dibidang agribisnis, yang disingkat dengan nama Bali Fresh Female Farmers Group (BFFFG), di daerah Karangasem dan Kintamani. Hubungan kemitraan yang terjalin antara PT. DIF Nusantara (sebagai pemasar) dengan BFFFG disebut Bali Fresh Female Farmers Partnership (BFFFP). Tujuan dari proyek BFFFP adalah : meningkatkan produksi per $\mathrm{m}^{2}$, mengoptimalkan penggunaan sumberdaya (air dan tanah) yang tepat guna, memilih lokasi yang tepat untuk digunakan memproduksi sayuran, memperbaiki pengetahuan petani, menurunkan biaya produksi per $\mathrm{kg}$ sayuran, memberikan kemudahan pasar kepada petani, dan meningkatkan pendapatan petani.

Kemitraan dijalin dengan wanita karena memang sudah menjadi budaya di
Bali bahwa wanita adalah pencari nafkah keluarga. Sebelum para wanita ini bergabung dalam kemitraan, mereka bekerja sebagai pedagang dan buruh proyek jalanan yang mendapatkan penghasilan tidak tetap dalam periode waktu tertentu. Disisi lain, untuk PT.DIF Nusantara bisa mendapatkan pasokan sayuran segar dari BFFFG dalam jumlah yang sesuai dengan permintaan. Tanpa kemitraan dengan BFFFG maka PT.DIF Nusantara akan kesulitan mendapatkan pasokan sayuran segar. Penelitian ini bertujuan untuk mengidentifikasi faktorfaktor internal dan eksternal dalam BFFFP, menyusun alternatif strategi dengan melakukan analisis SWOT, dan menganalisis faktor-faktor yang mempengaruhi curahan kerja wanita tani dalam BFFFG.

\section{BAHAN DAN METODE}

Penelitian ini dilaksanakan di kelompok tani wanita "Bali Fresh" yang berlokasi di Desa Kedisan, Kecamatan Kintamani, Kabupaten Bangli, Provinsi Bali. Pelaksanaan penelitian ini dilakukan mulai tanggal 12 Juni sampai 2 Oktober 2006. Pemilihan lokasi penelitian dilakukan secara sengaja (purposive), dengan pertimbangan bahwa kelompok tani wanita "Bali Fresh" ini memproduksi jenis sayuran yang komersial dengan menggunakan teknologi modern (Green House, Netting House, Tunnel House, Nurcery, dan Irrigation) yang sebelumnya belum ada, dan mengusahakan jenis sayuran komersial di daerah tersebut. Selain itu juga di proyek ini khususnya didaerah Kintamani dan Karangasem sangat menarik perhatian, karena tenaga kerja yang dipakai adalah para wanita yang melakukan proses produksinya.

Data yang dikumpulkan meliputi data primer dan data sekunder. Data primer diperoleh melalui wawancara langsung dengan petani, staff, dan observasi (pengamatan langsung dilapangan), diskusi, dan pengisian kuesioner. Data sekunder diperoleh dari 
Kantor Perbekel Kintamani (Kelurahan Kintamani) mengenai keadaan penduduk dan lokasi penelitian, data BPS, data dari Departemen Pertanian, skripsi terdahulu, internet, dan literatur-literatur yang berkaitan dengan penelitian.

Metode yang digunakan dalam penelitian ini adalah metode sensus. Jumlah responden seluruhnya 74 orang. Responden yang dijadikan sampel di PT. DIF Nusantara adalah Bagian Pemasaran 1 orang, dan Bagian Keuangan (Administrasi) 1 orang, Manager Lapangan BFFFG 1 orang, dan 1 orang dari PT. JORO. Serta dari pihak luar seperti keluarga 18 orang (kepada suami petani mitra, cucu, dan mertuanya), pemerintahan 2 orang (kepada Kepala Desa setempat dan pegawai Hubungan Masyarakat (HUMAS)), pedagang 2 orang, dan tetangga 15 orang serta 34 petani mitra.

Metode yang digunakan untuk mengidentifikasi kekuatan dan kelemahan (analisis kondisi internal) adalah Matriks IFE (Internal Factor Evaluation). Metode untuk identifikasi peluang dan ancaman (analisis kondisi ekstenal) adalah dengan menggunakan Matriks EFE (Eksternal Factor Evaluation). Perumusan strategi dilakukan dengan menggunakan matriks SWOT, yang merumuskan strategi perusahaan berdasarkan pada logika identifikasi strategi yang dapat memaksimalkan kekuatan (Strengths) dan peluang (Opportunities), namun secara bersamaan dapat meminimalkan kelemahan (Weaknesses) dan ancaman (Threats).

\section{HASIL DAN PEMBAHASAN}

\section{Gambaran Umum PT DIF Nusantara}

PT. DIF (Dimas International

Food-Supplier) Nusantara berdiri pada tanggal 1 Oktober 2000, yang berlokasi di Jl. Tukad Balian No. 133 RenonDenpasar-Bali. Sasaran utama PT. DIF Nusantara, yaitu memasarkan semua produk jenis hasil pertanian dari JORO GROUP dan petani ke restoran, cafe, hotel, supermaket dan supplier lain yang berada di wilayah Bali. Selain itu juga PT. DIF Nusantara memasarkan semua jenis hasil pertanian, seperti : sayur-sayuran, buah-buahan, telur, dsb sesuai dengan permintaan konsumen. PT. DIF Nusantara juga mengantarkan langsung ke tempat konsumen sesuai waktu yang sudah menjadi kesepakatan bersama dan memasarkan produknya dari PT. DIF Nusantara ini dengan nama merek "Bali Fresh".

Sumberdaya yang dimiliki PT. DIF Nusantara terdiri atas sumberdaya fisik dan sumberdaya manusia. Sumberdaya fisik PT. DIF Nusantara terdiri atas : bangunan, sarana dan prasarana yang mendukung kegiatan operasional maupun kegiatan pemasaran. Bangunan terdiri atas : gedung kantor, gudang (tempat kegiatan pengemasan dan penyimpanan bahan baku), mess untuk tempat tinggal karyawan, tempat parkir dan dapur. Sedangkan sarana dan prasarana yang mendukung kegiatan operasional dan kegiatan pemasaran terdiri atas : perlengkapan, peralatan dan alat transportasi, mesin pendingin (tempat menyimpan sayuran dari hasil panen dengan memakai keranjang), mesin pencuci sayuran, mesin pengering sayuran, mesin press.

Fasilitas kesejahteraan yang diberikan PT. DIF Nusantara bagi karyawannya diantaranya, yaitu : penggantian biaya pengobatan bila sakit (JAMSOSTEK), makan sebanyak 3 kali sehari atau lebih, dan mess untuk tempat tinggal karyawan. Dalam setiap seminggu para karyawan ini diberi libur 1,5 hari yang telah disepakati bersama antara karyawan dengan kepala bagian dan 5,5 hari kerja dalam seminggu.

\section{Gambaran Umum Bali Fresh Female Farmers Group ( BFFFG )}

BFFFG merupakan kelompok tani yang terdiri atas para petani wanita yang memproduksi sayur-sayuran segar yang bermerek Bali Fresh. Dalam BFFFG 
terdapat empat kelompok tani wanita yang terdiri atas : kelompok tani wanita yang memproduksi sayuran selada, sayuran tomat, paprika, dan timun mini.

Kelompok tani wanita " Bali Fresh " yang berada di Kintamani berjumlah 27 orang. Fasilitas yang disediakan untuk kelompok tani ini berupa kebun Penelitian dan Pengembangan (Research and Developmnent) seluas $6.500 \mathrm{~m}^{2}$, tempat pembibitan seluas $500 \mathrm{~m}^{2}$, lahan produksi untuk petani mitra di Kintamani seluas $7.500 \mathrm{~m}^{2}$, dan sarana produksi (pupuk, pestisida, benih, dan alat-alat pertanian), juga untuk paprika adanya dua Green House, yaitu : green house I seluas 3.360 $\mathrm{m}^{2}$ dan green house II seluas $1.140 \mathrm{~m}^{2}$, serta ada juga tempat pembibitannya khusus untuk paprika seluas $380 \mathrm{~m}^{2}$ lengkap dengan peralatan yang disediakan. Di lokasi Kintamani ini menghasilkan jenis sayuran, seperti : broccolli, ruccolla, lolobionda, loloroso, green oak leaf, read oak leaf, baby romain, batavia red, frize, dan coriander. Ini dilakukan dengan cara sistem non hidroponik dan setiap petani di Kintamani ini mempunyai tugas memelihara tanaman didalam tunnel house, netting house maupun out door dengan luas lahan seluas $\pm 500 \mathrm{~m}^{2}$ per orang.

Selain kelompok tani di Kintamani, juga ada kelompok tani yang berada di Karangasem yang berdiri pada tahun 2004. Petani disini ada 7 orang dan jenis sayuran yang dihasilkannya, antara lain : tomat cherry, terong, melon, timun mini, cabai merah keriting, dan tomat beef. Ini semua dengan cara sistem hidroponik, dan lahan produksi di Karangasem seluas $1.400 \mathrm{~m}^{2}$ serta setiap petani mitra di Karangasem mempunyai tugas memelihara tanaman di dalam green house seluas \pm $200 \mathrm{~m}^{2}$.

\section{Karakteristik Umum Responden Petani Mitra "Bali Fresh"}

Karakteristik umum responden petani mitra "Bali Fresh" yang diamati dalam penelitian ini, meliputi : usia, tingkat pendidikan terakhir, jumlah tanggungan keluarga, jenis pekerjaan sebelum bermitra, pendapatan anggota keluaga, tingkat pendapatan petani mitra, dan pengambilan keputusan.

Responden petani mitra "Bali Fresh" untuk kelompok usia, sebagian besar berusia 20-29 tahun, yaitu sebanyak 41,1\%. Dari 34 responden petani mitra "Bali Fresh", sebagian besar responden ini berpendidikan tamatan SD sebanyak 16 responden $(47 \%)$. Jenis pekerjaan sebelum bermitra bagi petani sangat bervariasi, dan jenis pekerjaan yang paling banyak yaitu sebagai petani sebanyak 10 responden $(29,4 \%)$.

Tingkat pendapatan semua anggota keluarga dalam satu bulan mayoritas Rp. 900.000 sebanyak 7 responden $(20,5 \%)$. Tingkat pendapatan petani dalam satu bulan mayoritas berada pada Rp. 400.000 - Rp. 499.999 (sebanyak 13 responden atau 38,2\%). Pengambilan keputusan untuk bekerja di proyek BFFFP ini di dominasi paling banyak didukung oleh semua anggota keluarga sebanyak 17 responden $(50 \%)$, peringkat kedua keputusan sendiri sebanyak 15 responden $(44,1 \%)$.

\section{Analisis Lingkungan Internal dan Matriks IFE PT. DIF Nusantara}

Pada Tabel 1 terlihat bahwa terdapat sembilan kekuatan dan dua kelemahan dan dapt dilihat pula nilai paling tinggi pertama (0.748) yaitu pelayanan dan pengiriman yang baik dan nilai tertinggi kedua (0.680) yaitu adanya kekompakan team work. Dalam lingkungan internal ini PT. DIF Nusantara terdapat beberapa kekuatan, diantaranya : memiliki good will yang dikenal konsumen, jenis sayuran yang sesuai dengan permintaan konsumen, adanya kekompakkan team work, memiliki Technical Advisers yang handal, memberikan bimbingan kepada petani mitra, sarana pasca panen yang cukup memadai, pelayanan dan pengiriman yang baik, saling mendukung antar pegawai, 
dan mampu menjamin pemasaran. Selain kekuatan, ada kelemahan dari lingkungan internal PT. DIF Nusantara, antara lain : banyak sayuran yang tidak terpakai / terbuang, dan over produksi dari hasil panen petani mitra. Hasil akhir matriks IFE PT DIF Nusantara adalah 3,972.

Tabel 1. Perhitungan Matriks IFE PT. DIF Nusantara, Tahun 2006

\begin{tabular}{llccc}
\hline \multicolumn{1}{c}{ Faktor Internal } & Bobot & Rating & Nilai \\
\hline & Kekuatan & & & \\
A. & Memiliki good will yang dikenal konsumen & 0.125 & 2 & 0.250 \\
B. & Kualitas sayuran yang sesuai dengan permintaan konsumen & 0.107 & 3 & 0.321 \\
C. & Adanya kekompakkan team work & 0.170 & 4 & 0.680 \\
D. & Memiliki Technical Advisers yang handal & 0.039 & 4 & 0.156 \\
F. & Sarana pasca panen yang cukup memadai & 0.096 & 4 & 0.384 \\
G. & Pelayanan dan pengiriman yang baik & 0.187 & 4 & 0.748 \\
H. & Saling mendukung antar pegawai & 0.113 & 4 & 0.452 \\
I. & Mampu menjamin pemasaran & 0.113 & 4 & 0.452 \\
& Kelemahan & & & \\
J. & Banyak sayuran yang tidak terpakai / terbuang & 0.062 & 3 & 0.186 \\
K. & Over produksi dari hasil panen petani mitra & 0.113 & 2 & 0.226 \\
\hline & \multicolumn{1}{c}{ Total } & $\mathbf{1 . 0 0 0}$ & & $\mathbf{3 . 9 7 2}$ \\
\hline
\end{tabular}

Analisis Lingkungan Internal dan Matriks IFE Bali Fresh Female Farmers Group (BFFFG)

Pada Tabel 2 terlihat bahwa

terdapat delapan kekuatan dan sembilan kelemahan. Dalam lingkungan internal ini BFFFG terdapat beberapa kekuatan, diantaranya :

Tabel 2. Perhitungan Matriks IFE BFFFG, Tahun 2006

\begin{tabular}{llccc}
\hline & \multicolumn{1}{c}{ Faktor Internal } & Bobot & Rating & Nilai \\
\hline & Kekuatan & & & \\
A. & Adanya jamsostek & 0.064 & 4 & 0.257 \\
B. & Petani mitra pekerja keras & 0.064 & 4 & 0.257 \\
C. & Mendapatkan pekerjaan tetap & 0.061 & 3 & 0.184 \\
D. & Ketersediaan lahan yang cukup & 0.070 & 3 & 0.211 \\
E. & Adanya dukungan masyarakat, pemerintah, dan keluarga & 0.082 & 4 & 0.331 \\
F. & Proyek pertama berdiri & 0.079 & 2 & 0.159 \\
G. & Keinginan untuk merima inovasi baru & 0.061 & 2 & 0.122 \\
H. & Tidak boleh ada tenaga kerja laki-laki sebagai petani mitra & 0.085 & 3 & 0.257 \\
& Kelemahan & & & \\
I. & Rutinitas pertemuan Technical Advisers dengan petani mitra & 0.015 & 1 & 0.015 \\
J. & Tingkat pendidikan petani mitra & 0.067 & 2 & 0.134 \\
K. & Pengetahuan dan keterampilan petani mitra & 0.055 & 2 & 0.110 \\
L. & Kurangnya tenaga kerja di tempat pembibitan & 0.049 & 1 & 0.049 \\
M. & Kurangnya alat-alat pertanian tradisional & 0.079 & 1 & 0.079 \\
N. & Ketidaktahuan masyarakat akan sayuran komersil ini & 0.061 & 4 & 0.245 \\
O. & Banyak ibu mitra yang mempunyai anak balita & 0.068 & 4 & 0.257 \\
P. & Belum transparannya harga hasil panen & 0.064 & 4 & 0.260 \\
Q. & Jadwal tanam belum sesuai & 0.061 & 1 & 0.061 \\
\hline & $\quad$ Total & $\mathbf{1 . 0 0 0}$ & & $\mathbf{2 . 9 8 8}$ \\
\hline
\end{tabular}


adanya jamsostek, petani mitra pekerja keras, mendapatkan pekerjaan tetap, ketersediaan lahan yang cukup, adanya dukungan masyarakat, pemerintah, dan keluarga, proyek pertama berdiri, keinginan untuk menerima inovasi baru, dan tidak boleh ada tenaga kerja laki-laki sebagai petani mitra. Sedangkan kelemahannya, antara lain : rutinitas pertemuan pertemuan Technical Advisers dengan petani mitra, tingkat pendidikan petani mitra, pengetahuan dan keterampilan petani mitra, kurangnya tenaga kerja di tempat pembibitan, kurangnya alat-alat pertanian tradisional, ketidaktahuan masyarakat akan sayuran komersil ini, banyak ibu mitra yang mempunyai anak balita, belum transparannya harga hasil panen, dan jadwal tanam belum sesuai.

Dari perhitungan matriks IFE PT. DIF Nusantara diperoleh nilai sebesar 3.972 dan BFFFG diperoleh nilai sebesar dan 2.988. Angka tersebut menunjukkan bahwa posisi perusahaan berada pada kondisi kuat, dan BFFFG didalam lingkungan ini berada pada kondisi ratarata, karena terutama sekali baru pertama proyek ini berdiri di daerah Kintamani dan Karangasem dan berkembang untuk menjadi lebih baik, dan banyak dukungan dari beberapa pihak yang merespon dengan positif adanya proyek di daerah tersebut.

\section{Analisis Lingkungan Eksternal dan Matriks EFE PT. DIF Nusantara}

Pada Tabel 3 di bawah ini terlihat bahwa terdapat empat peluang dan tiga ancaman. Jika dilihat dari nilai paling tinggi (0.493) bahwa banyak konsumen / pelanggan yang sudah menjadi langganan tetap PT. DIF Nusantara seperti restoran, cafe, hotel, dan beberapa pasar swalayan yang kebanyakan para turis mancanegara yang menyukai sayuran, seperti selada (lettuce), brokoli, paprika dan tomat cherry.

Tabel 3. Perhitungan Matriks EFE PT. DIF Nusantara

\begin{tabular}{llccc}
\hline \multicolumn{1}{c}{ Faktor Eksternal } & Bobot & Rating & Nilai \\
\hline & Peluang & 0.246 & 2 & 0.493 \\
A. & Banyak konsumen / pelanggan & 0.109 & 2 & 0.219 \\
B. Perdagangan ke antar pulau & 0.095 & 2 & 0.191 \\
C. Memiliki relasi dengan perusahaan Luar & & & \\
& $\begin{array}{l}\text { Negeri } \\
\text { D. Menarik perhatian konsumen }\end{array}$ & 0.273 & 1 & 0.273 \\
E. Ancaman & & 3 & 0.821 \\
F. Ada pesaing yang membuka usaha yang sama & 0.273 & 3 & 0.821 \\
Geterlambatan pembayaran dari konsumen & 0.273 & & 0.821 \\
\hline & $\begin{array}{l}\text { Secara kredit } \\
\text { Terubahan harga-harga sayuran }\end{array}$ & 0.273 & 3 & $\mathbf{3 . 6 3 9}$ \\
\hline
\end{tabular}

Dalam lingkungan eksternal ini PT. DIF Nusantara terdapat beberapa peluang, diantaranya : perdagangan ke Luar Negeri atau antar pulau, memiliki relasi dengan perusahaan Luar Negeri, dan menarik perhatian konsumen. Selain peluang, ada juga ancaman, antara lain : ada pesaing yang membuka uasaha yang sama, keterlambatan pembayaran dari konsumen dan secara kredit, dan perubahan hargaharga sayuran. Nilai matriks EFE PT DIF Nusantara adalah 3,639.

\section{Lingkungan Eksternal dan Matriks EFE Bali Fresh Female Farmers Group (BFFFG) \\ Pada Tabel 4 terlihat bahwa} terdapat lima kekuatan dan lima 
kelemahan. Jika dilihat dari nilai paling tinggi pertama (0.360) yaitu besarnya UMR yang sesuai (C), hal ini menjadi peluang karena pendapatan petani mitra bisa sesuai dengan UMR di daerah kintamani dan karangasem. Bahkan bisa juga sedikit lebih tinggi untuk lebih membantu perekonomian keluarga petani mitra.

Dalam lingkungan eksternal ini BFFFG terdapat beberapa peluang, diantaranya : adanya penelitian, dapat menyekolahkan anak petani mitra, banyak ibu-ibu yang ingin bergabung, dan dapat mengurangi pengangguran. Sedangkan ancamannya, antara lain : adanya kecemburuan sosial atau rasa intrik dari masyarakat, penyeleksian sebelum masuk kerja, dan diperlukan izin pemerintah daerah setempat. Dari perhitungan matriks EFE PT. DIF Nusantara diperoleh nilai sebesar 3.639 dan BFFFG diperoleh nilai sebesar dan 2.512 .

Tabel 4. Perhitungan Matriks EFE BFFFG

\begin{tabular}{clccc}
\hline \multicolumn{1}{c}{ Faktor Eksternal } & Bobot & $\begin{array}{c}\text { Ratin } \\
\text { g }\end{array}$ & Nilai \\
\hline & Peluang & & & \\
A. & Adanya penelitian & 0.111 & 2 & 0.223 \\
B. & Dapat menyekolahkan anak petani mitra & 0.094 & 1 & 0.094 \\
C. & Besarnya UMR yang sesuai & 0.120 & 3 & 0.360 \\
D. & Banyak ibu-ibu yang ingin bergabung & 0.085 & 2 & 0.171 \\
E. Dapat mengurangi pengangguran & 0.090 & 2 & 0.180 \\
& & & \\
F. Ancaman & Adanya kecemburuan sosial atau rasa & 0.120 & 4 & 0.480 \\
& intrik dari masyarakat & 0.124 & 4 & 0.497 \\
G. & Takut kegagalan panen & 0.085 & 2 & 0.171 \\
H. & Penyeleksian sebelum masuk kerja & 0.081 & 4 & 0.326 \\
I. Diperlukan izin pemerintah daerah & & & \\
\hline & Tetempat & $\mathbf{1 . 0 0 0}$ & & $\mathbf{2 . 5 1 2}$ \\
\hline
\end{tabular}

Angka tersebut menunjukkan bahwa posisi perusahaan berada pada kondisi kuat, dan BFFFG didalam lingkungan ini berada pada kondisi ratarata, karena mempunyai pengaruh yang besar terhadap masyarakat luas dengan adanya proyek yang berada didaerah ini, dan dari faktor eksternal ini sedikit banyaknya bisa memberikan masukanmasukan yang positif untuk lebih memperbaiki jika terjadi kesalahan dalam proyek ini.

\section{Matriks IE PT. DIF Nusantara}

Apabila dilihat dari pihak PT. DIF Nusantara, ini berada pada sel 1 dan menunjukkan posisi perusahaan sendiri secara internal / eksternal berada cukup baik pula, sehingga strategi yang disarankan adalah strategi pertumbuhan.

Bila secara faktor eksternal yang menjadi perhatian banyak pihak, seperti : tetangga, family, pemerintahan, dan pedagang ini semua sangat mendukung sekali dengan adanya proyek di daerah Kintamani dan Karangasem, karena ini adalah proyek pertama berdiri dan diharapkan bisa tetap berlanjut untuk masa depan kehidupan petani mitra sendiri. Semua ini berdampak positif dengan keberadaan proyek ibu-ibu tersebut. Matriks ini dapat dilihat pada Gambar 1. 


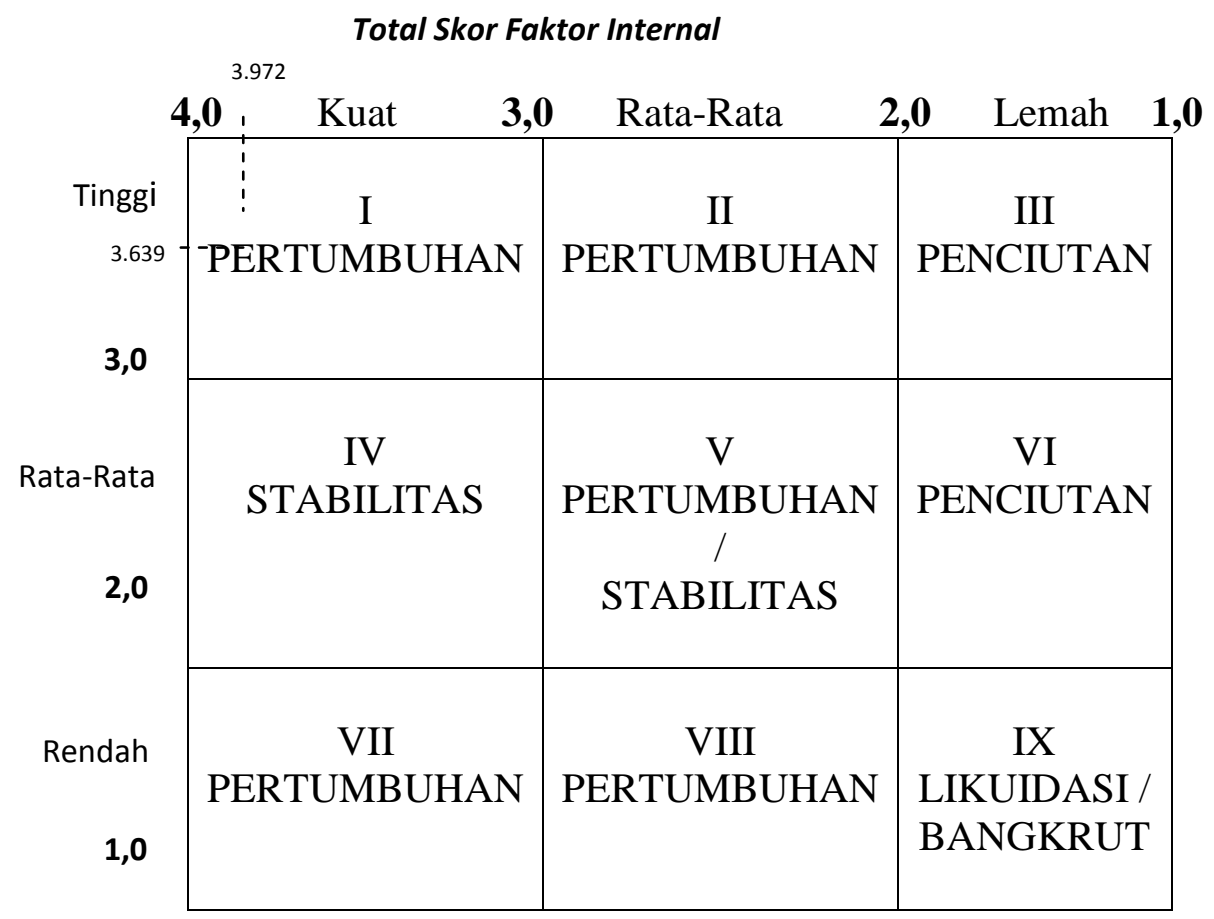

Gambar 1 Matriks IE ( Internal - Eksternal) PT. DIF Nusantara

\section{Matriks IE BFFFG}

Apabila dilihat dari pihak BFFFG, ini berada pada sel $\mathrm{V}$ dan menunjukkan posisi BFFFG sendiri secara internal / eksternal berada cukup baik pula, sehingga strategi yang disarankan adalah strategi pertumbuhan.

\section{Total Skor Faktor Internal}

\begin{tabular}{|c|c|c|c|}
\hline & Kuat & $\begin{array}{l}2.988 \\
\text { Rata-Rata }\end{array}$ & Lemah \\
\hline Tinggi & $\begin{array}{c}\text { I } \\
\text { PERTUMBUHAN }\end{array}$ & $\begin{array}{c}\text { II } \\
\text { PERTUMBUHAN }\end{array}$ & $\begin{array}{c}\text { III } \\
\text { PENCIUTAN }\end{array}$ \\
\hline $\begin{array}{l}\text { Rata-Rata } \\
\mathbf{2 . 5 1 2}\end{array}$ & $\begin{array}{c}\text { IV } \\
\text { STABILITAS }\end{array}$ & $\begin{array}{c}\mathrm{V} \\
\text { PERTUMBUHAN } \\
/ / \\
\text { STABILITAS } \\
\end{array}$ & $\begin{array}{c}\text { VI } \\
\text { PENCIUTAN }\end{array}$ \\
\hline Rendah & $\begin{array}{c}\text { VII } \\
\text { PERTUMBUHAN }\end{array}$ & $\begin{array}{c}\text { VIII } \\
\text { PERTUMBUHAN }\end{array}$ & $\begin{array}{c}\text { IX } \\
\text { LIKUIDASI / } \\
\text { BANGKRUT }\end{array}$ \\
\hline
\end{tabular}

Gambar 2. Matriks IE ( Internal - Eksternal) BFFFG

Dalam posisi internal / eksternal dari BFFFG lebih meningkatkan cara kerja petani mitra supaya bisa menghasilkan kuantitas yang bagus dan sesuai dengan permintaan PT. DIF Nusantara juga sesuai dengan prediksi panen yang telah ditentukan jangan sampai terjadi over produksi sayuran, yang mengakibatkan sayuran banyak yang layu dan terbuang dengan percuma sehingga tidak terpakai. 
Dengan demikian walaupun BFFFG ini baru berdiri dan berkembang, tapi sudah bisa mempunyai pengaruh yang positif dikalangan masyarakat luas, pemerintahan juga bagi petani mitra sendiri untuk memperbaiki kehidupan petani menjadi lebih baik dari sebelumnya, dan bisa membiayai anak-anaknya bersekolah. Matriks ini dapat dilihat pada Gambar 2.

\begin{abstract}
Matriks SWOT Bali Fresh Female Farmers Partnership (BFFFP)

Setelah diketahui posisi dari masing-masing pihak yang bermitra melalui matriks IE, maka dilakukan pencocokan dengan menggunakan matriks SWOT, yaitu : melalui pengembangan empat tipe strategi kemitraan, antara lain :

(1) Strategi Strenghts-Opportinities (SO), (2) Strategi Strenghts-Threats (ST), (3) Strategi Weaknesses-Opportinities (WO), (4) Strategi Weaknesses-Threats (WT). Ini dapat dilihat pada Tabel 5
\end{abstract}

Tabel 5. Matriks SWOT PT. DIF Nusantara

\begin{tabular}{|c|c|c|}
\hline $\begin{array}{l}\text { Faktor Internal } \\
\text { Faktor Eksternal }\end{array}$ & $\underline{\text { Kekuatan }(\mathbf{S})}$ & $\underline{\operatorname{Kelemahan}(\mathbf{W})}$ \\
\hline & $\begin{array}{l}\text { 1. Adanya kekompakkan team work } \\
\text { 2. Saling mendukung antar pegawai } \\
\text { 3. Sarana pasca panen yang cukup } \\
\text { memadai } \\
\text { 4. Kualitas sayuran yang sesuai dengan } \\
\text { permintaan konsumen } \\
\text { 5. Pelayanan dan pengiriman yang baik }\end{array}$ & $\begin{array}{l}\text { 1. Terlalu over produksi dari hasil } \\
\text { panen petani mitra } \\
\text { 2. Banyak sayuran yang tidak } \\
\text { terpakai / terbuang }\end{array}$ \\
\hline Peluang $(\mathrm{O})$ & Strategi $(\mathbf{S}-\mathbf{O})$ & Strategi $(\mathrm{W}-\mathbf{O})$ \\
\hline $\begin{array}{l}\text { 1. Banyak konsumen / } \\
\text { pelanggan } \\
\text { 2. Perdagangan ke antar pulau } \\
\text { 3. Mampu menarik perhatian } \\
\text { konsumen } \\
\text { 4. Memiliki relasi dengan } \\
\text { perusahaan Luar Negeri }\end{array}$ & $\begin{array}{l}\text { 1. Meningkatkan kembali kualitas } \\
\text { produk yang sesuai di mata konsumen } \\
\text { dengan tim pekerja yang kompak, dan } \\
\text { pelayanan pengiriman yang tidak } \\
\text { mengecewakan konsumen dengan } \\
\text { banyak dukungan }\left(\mathrm{S}_{1}, \mathrm{~S}_{4}, \mathrm{~S}_{5}, \mathrm{O}_{1}, \mathrm{O}_{3}\right) \\
\text { 2. Dapat memperkenalkan produk Bali } \\
\text { Fresh ini ke luar pulau Bali, dengan } \\
\text { sarana pasca panen yang cukup baik } \\
\text { untuk mengemas produk tersebut } \\
\text { supaya lebih menarik }\left(\mathrm{S}_{3}, \mathrm{O}_{2}, \mathrm{O}_{4}\right)\end{array}$ & $\begin{array}{l}\text { 1. Dapat mencari konsumen baru } \\
\text { dengan produk Bali Fresh ini } \\
\left(\mathrm{W}_{1}, \mathrm{~W}_{2}, \mathrm{O}_{1}, \mathrm{O}_{3}\right)\end{array}$ \\
\hline Ancaman $(T)$ & Strategi $(\mathbf{S}-\mathbf{T})$ & Strategi $(\mathbf{W}-\mathbf{T})$ \\
\hline $\begin{array}{l}\text { 1. Keterlambatan pembayaran } \\
\text { dari konsumen secara kredit } \\
\text { 2. Perubahan harga-harga } \\
\text { sayuran } \\
\text { 3. Ada pesaing yang } \\
\text { membuka usaha yang sama }\end{array}$ & $\begin{array}{l}\text { 1. Dapat mengurangi waktu pembayaran } \\
\text { dari pelanggan, supaya lebih cepat } \\
\text { dalam melunasi pembayarannya } \\
\text { dengan tenaga penagihan yang cukup } \\
\left(\mathrm{S}_{1}, \mathrm{~S}_{5}, \mathrm{~T}_{1}\right) \\
\text { 2. Bisa bertukar informasi yang positif } \\
\text { disaat ada yang membuka usaha yang } \\
\text { sama dengan dukungan, dari jenis } \\
\text { sayuran yang berbeda, dan tetap } \\
\text { menjaga strategi pemasaran } \\
\text { perusahaan supaya tidak diketahui } \\
\text { oleh pihak luar }\left(\mathrm{S}_{2}, \mathrm{~S}_{4}, \mathrm{~T}_{3}\right)\end{array}$ & $\begin{array}{l}\text { 1. Dapat memanfaatkan sayuran } \\
\text { yang hampir tidak terpakai atau } \\
\text { sedikit agak layu dan bisa di } \\
\text { sortir kembali, untuk membuka } \\
\text { peluang yang baru dan dikemas } \\
\text { menarik dalam keadaan tetap } \\
\text { terjaga kesegarannya }\left(\mathrm{S}_{3}, \mathrm{~S}_{4}, \mathrm{~T}_{2},\right. \\
\left.\mathrm{T}_{3}\right)\end{array}$ \\
\hline
\end{tabular}


Matriks SWOT BFFFG

Selain bisa melihat beberapa alternatif strategi dari PT. DI Nusantara, juga dapat dilihat dari matriks SWOT BFFFG seperti pada Tabel 6 di bawah ini :

Tabel 6. Matriks SWOT BFFFG

\begin{tabular}{ll}
$\begin{array}{l}\text { Faktor Internal } \\
\text { Faktor Eksternal }\end{array}$ & \multicolumn{1}{c}{$\underline{\text { Kekuatan (S) }}$} \\
\hline & \\
& 1. Adanya dukungan pemerintah, \\
masyarakat, dan keluarga \\
2. Proyek pertama berdiri \\
3. Ketersediaan lahan yang cukup \\
4.Adanya jamsostek \\
5. Petani mitra pekerja keras
\end{tabular}

\section{Peluang (O)}

1. Adanya penelitian

2. Dapat menyekolahkan anak

3. petani mitra

4. Besarnya UMR yang sesuai

5. Banyak ibu-ibu yang ingin bergabung

6. Dapat mengurangi pengangguran

\section{Ancaman (T)}

1. Adanya kecemburuan sosial

2. Takut kegagalan panen

3. Penyeleksian sebelum masuk kerja

4. Diperlukan izin kepada pemerintah daerah setempat

\section{Strategi $(\mathbf{S}-\mathbf{O})$}

1. Dapat memperkenalkan lagi keberadaan BFFFG yang pertama kali ke masyarakat luas, banyak dukungan, serta dapat mengurangi penganggguran bagi para ibu dengan informasi yang jelas, dan salah satu contohnya dari hasil penelitian dan mampu menarik para ibu ikut bergabung $\left(\mathrm{S}_{1}, \mathrm{~S}_{2}\right.$, $\mathrm{O}_{1}, \mathrm{O}_{4}, \mathrm{O}_{5}$ )

2. Peningkatan pendapatan petani dan diringankan beban dengan adanya jamsostek $\left(\mathrm{S}_{4}, \mathrm{~S}_{5}, \mathrm{O}_{3}\right)$

3. Memenuhi kebutuhan anak untuk sekolah dengan kerja keras dan keinganan pemberian jamsostek $\left(\mathrm{S}_{3}, \mathrm{~S}_{4}, \mathrm{O}_{2}\right)$

\section{Strategi ( S - T)}

1. Adanya dukungan dan harus ada izin walaupun tidak secara tertulis, supaya pemerintah pun dapat bertanggungjawab dan mengetahui dengan adanya BFFFG di daerah tersebut $\left(\mathrm{S}_{1}, \mathrm{~S}_{2}\right.$, $\mathrm{T}_{4}$ )

2. Mengumpulkan para calon ibu mitra yang ingin bergabung dan diseleksi kembali untuk berapa jumlah petani yang dibutuhkan, supaya tidak ada kecemburuan $\left(\mathrm{S}_{2}, \mathrm{~T}_{1}, \mathrm{~T}_{3}\right)$

3. Meningkatkan kerja petani mitra dengan giat dan tekun untuk menghindari sedikit kesalahan bila terjadi kegagalan panen $\left(S_{3}\right.$, $\mathrm{S}_{5}, \mathrm{~T}_{2}$ )
1. Tingkat pendidikan petani mitra

2. Pengetahuan dan keterampilan petani mitra

3. Kurangnya alat-alat pertanian tradisional

4. Banyak ibu mitra yang mempunyai anak balita

5. Belum transparannya harga hasil panen

6. Kurangnya tenaga kerja di tempat pembibitan

\section{Strategi $(\mathbf{W}-\mathbf{O})$}

1. Meningkatkan cara kerja petani mengenai jenis sayuran yang ditanam dari hasil contoh para penelitian, dan menambah tenaga kerja di tempat pembibitan yang lebih muda, menambah alat-alat pertanian tradisional sehingga dapat menyerap tenaga petani lebih banyak $\left(\mathrm{W}_{1}, \mathrm{~W}_{2}, \mathrm{~W}_{3}, \mathrm{~W}_{6}, \mathrm{O}_{1}\right.$, $\mathrm{O}_{6}$ )

2. Lebih terbuka lagi pada petani tentang harga panen dan mencari calon ibu mitra yang penghasilannya sesuai dengan $\operatorname{UMR}\left(\mathrm{W}_{5}, \mathrm{O}_{3}, \mathrm{O}_{4}, \mathrm{O}_{5}\right)$

3. Diadakannya tempat berupa sarana bermain bagi anak balita petani mitra $\left(\mathrm{W}_{4}, \mathrm{O}_{2}\right)$

\section{Strategi $(\mathbf{W}-\mathbf{T})$}

1. Mencari tenaga kerja yang muda, berpendidikan, dan terseleksi engan baik sehingga tidak ada rasa curiga $\left(\mathrm{W}_{1}, \mathrm{~W}_{2}\right.$, $\mathrm{W}_{3}, \mathrm{~W}_{6}, \mathrm{~T}_{1}, \mathrm{~T}_{3}$ )

2. Sebaiknya didirikan sarana taman kanak-kanak, dan harus transparan harga hasil panen pada petani mitra $\left(\mathrm{W}_{4}, \mathrm{~W}_{5}, \mathrm{~T}_{2}\right.$, $\mathrm{T}_{4}$ ) 
Dalam penelitian ini selain menggunakan analisis SWOT yang bisa dilihat kekuatan, kelemahan, peluang, dan ancaman apa saja yang terjadi di BFFFP tersebut terutama secara faktor eksternalnya yang lebih dominan yang diduga dapat mempengaruhi jalannya kemitraan ini, juga pada penelitian ini bisa dilihat faktorfaktor yang mempengaruhi curahan kerja petani mitra "Bali Fresh" dengan menggunakan rumus model regresi linier berganda.

\section{KESIMPULAN DAN IMPLIKASI KEBIJAKAN}

\section{Kesimpulan}

1. Faktor-faktor yang mempengaruhi jalannya BFFFP baik dari segi internal, yaitu pelayanan dan pengiriman yang baik dari PT. DIF Nusantara dengan kekompakkan team work yang saling mendukung satu sama lain dan kelebihan hasil produksi sehingga banyak sayuran terbuang. Namun selain itu dari segi eksternalnya selalu ada kecemburuan sosial baik petani mitra dengan petani mitranya sendiri atau dengan warga sekitarnya yang ingin bergabung di kemitraan BFFFP, selalu ada rasa takut akan gagal panen, penyeleksian masuk kerja yang selektif dan harus ada izin pemerintah daerah setempat walaupun tidak secara tertulis.

2. Alternatif strategi untuk keberhasilan kemitraan yaitu dapat memperkenalkan produk "Bali Fresh" keluar pulau Bali, tetap menjaga strategi pemasaran perusahaan supaya tidak diketahui oleh pihak luar dan dapat memanfaatkan sayuran yang hampir tidak terpakai dan bisa disortir kembali untk membuka peluang baru yang dikemas menarik dalam keadaan tetap terjaga kesegarannya.

3. Curahan kerja wanita tani "Bali Fresh" pada kegiatan produktif dipengaruhi dengan nyata (signifikan) oleh usia, pendidikan dan pengalaman. Jumlah tanggungan keluarga, jumlah asset, dan pendapatan suami tidak berpengaruh nyata secara statistik terhadap curahan tenaga kerja wanita tani.

\section{Implikasi Kebijakan}

Dari hasil penelitian yang dilakukan, maka saran yang dapat diberikan yaitu :

1. Didirikannya sarana taman kanakkanak untuk balita petani mitra

2. Sebaiknya dapat menambah jumlah tenaga kerja atau petani di tempat pembibitan nursery yang lebih muda.

3. Sebaiknya untuk lebih transparan lagi mengenai harga hasil panen petani mitra, supaya bisa diketahui dengan jelas oleh petani mitra agar tidak menimbulkan rasa curiga pada perusahaan.

4. Sebaiknya bagi PT. DIF Nusantara, khususnya bagian pemasarannya (sales marketing) lebih meningkatkan lagi dalam mencari konsumen baru, sehingga tidak terlalu banyak sayuran yang terbuang.

\section{DAFTAR PUSTAKA}

Badan Pusat Statistik. 1994. Wanita, Ibu, dan Anak. BPS. Jakarta.

Badan Pengembangan Sumberdaya Manusia Pertanian. Deptan. 2004. Statistika Pertanian 2004. Pusat Data dan informasi Pertanian Departemen Pertanian. Jakarta.

Candra Puspita Arumardi Crispina. 2005. Curahan Kerja dan Kontribusi Pendapatan Kepala Keluarga Dalam Aktivitas Ekonomi Keluarga Pesesaan. Skripsi Jurusan Ilmu-Imu Sosial Ekonomi Pertanian. Fakultas Pertanian. IPB. Bogor.

Agustina (1994) dalam Candra Puspita Arumardi Crispina_2005. Curahan Kerja dan Kontribusi Pendapatan Kepala Keluarga Dalam Aktivitas Ekonomi Keluarga Pesesaan. Skripsi Jurusan Ilmu-Imu Sosial Ekonomi Pertanian. Fakultas Pertanian. IPB. Bogor.

Subaningrum (1998)_dalam.Candra Puspita Arumardi Crispina 2005. 
Curahan Kerja dan Kontribusi Pendapatan Kepala Keluarga Dalam Aktivitas Ekonomi Keluarga Pesesaan. Skripsi Jurusan Ilmu-Imu Sosial Ekonomi Pertanian. Fakultas Pertanian. IPB. Bogor.

Sudarijati (1993)_dalam Candra Puspita Arumardi Crispina 2005. Curahan Kerja dan Kontribusi Pendapatan Kepala Keluarga Dalam Aktivitas Ekonomi Keluarga Pesesaan. Skripsi Jurusan Ilmu-Imu Sosial Ekonomi Pertanian. Fakultas Pertanian. IPB. Bogor.

Hafsah M.J. 1999. Kemitraan Usaha Konsepsi dan Strategi. Sinar Harapan. Jakarta.

Munandar Enda. 2006. Pengaruh Jumlah Buah Per Tanaman dan Kultivar Terhadap Produksi danKualitas Buah Melon (Cucumis melo L.) Yang Ditanam Secara Hidroponik. Skripsi Jurusan Sosial Ekonomi Pertanian. Fakultas Pertanian. Universitas Djuanda. Bogor.

Rangkuti 2004. Analisis SWOT. Teknik Membedah Kasus Bisnis. PT. Gramedia Pustaka Utama. Jakarta.

Saladin Djaslim. 2004. Manajemen Strategi dan Kebijakan Perusahaan. Linda Karya. Bandung.

Wahyudi Achmad. 2006. Analisis Strategi Pemasaran Sayuran Segar di Pesantren Agro Nuur EL-Falah. Skripsi Jurusan Sosial Ekonomi Pertanian. Fakultas Pertanian. Universitas Djuanda. Bogor.

BPS. 2007. Jumlah Penduduk di Indonesia dan Bali. http:/www.bps.go.id. [20 Maret 2007].

BPS. 2006. Propinsi Bali (Hasil Registrasi Penduduk), http:/www.bps.go.id. dalam BPS (2006) [20 Maret 2007].

BPS. Bali. 2006. Statistik Wisatawan Mancanegara ke Bali (2004) / agriculture / dafta.htm, http:/www. bps bali..go.id.dalam (2006) [29 Januari 2006]. 